\title{
Testemunhos de Passagem
}

Sonia Guggisberg é Pós-doutoranda em Artes Visuais (ECA-USP, Bolsa CNPq-Capes); Doutora em Comunicação e Semiótica (PUC-SP, Bolsa Fapesp) e Mestre em Artes (Unicamp, Bolsa Capes). Artista, videomaker e pesquisadora, participando de mostras coletivas e individuais, palestras e workshops no Brasil e exterior desde os anos 1990. Foca questões do documentário artístico, com trabalhos em fotografia, site specific, videoinstalação, som. Realizou 18 exposições individuais e, além do Brasil, suas produções já foram exibidas em Nova York, Alemanha, México, Colômbia, Chile, Espanha e França. Obras nos museus Lasar Segall, de Arte Contemporânea-SP, da Cidade de São Paulo, SESC, Pinacoteca e Instituto Figueiredo Ferraz, entre outros. <contato@soniaguggisberg.com.br> ORCID: 0000-0002-0874-8019
Resumo $\mathrm{O}$ objetivo desta pesquisa é gerar propostas documentais em videoarte dentro do que este estudo chama de Documentação Performativa de Saberes ${ }^{1}$. Testemunhos de Passagem é uma instalação multicanais que se utiliza de tecnologias múltiplas para entrelaçar imagens, testemunhos e sons. Montado a partir de oito projeções coreografadas, sincronizadas com um sistema sonoro em seis canais, o projeto documenta, na forma ensaística, passagens e testemunhos de pessoas em situação de refúgio. Questões como a travessia, os vestígios, os sonhos, a espera no campo de refugiados e o futuro incerto integram este trabalho. É na intersecção entre dois contextos - arte política e hibridismo linguístico - que se pode apreender Testemunhos de Passagem. A interdisciplinaridade temática inspirada nas bases teóricas dos campos da arte, política e sociologia é formalmente espelhada pela liberdade com a qual esta pesquisa mistura tecnologia e arte documental.

Palavras chave Documentação performativa, Ecologia de saberes, Hibridismo tecnológico, Testemunho, Vulnerabilidade humana. 


\section{Passing Testimonies}

Abstract The purpose of this research is to generate video art documentary proposals within what this study calls Performative Documentation of Knowledge ${ }^{2}$. Passing Testimonies is a multichannel installation that uses multiple technologies to interweave images, testimonials and sounds. Assembled from eight choreographed projections, synchronized with a six-channel sound work, the project documents, in essay form, passages and testimonies of people in a refuge state. Issues such as crossing, traces, dreams, waiting in the refugee camp and the uncertain future are all part of this work. It is at the intersection between two contexts - political art and linguistic hybridity - that we can understand Passing Testimonies. The thematic interdisciplinarity inspired by the theoretical bases of the fields of art, politics and sociology is formally mirrored by the freedom with which this research mixes technology and documentary art.

Keywords Performative documentation, Ecology of knowledges, Technological hybridity, A testimony, Human vulnerability. 


\section{Sobre o Projeto}

Não há dúvidas de que o avanço audiovisual ampliou o campo de experimentação na arte, incorporando a produção tecnológica de imagens capaz de elaborar novas lógicas organizadoras. Testemunhos de Passagem apresenta palavras, imagens e sons que transitam, gerando um jogo de alternâncias e costuras. Trata-se de um documentário experimental construído por passagens do êxodo contemporâneo, a partir de imagens captadas em Malta, Lampeduza e Grécia entre os anos de 2014 e 2018.

Nesta instalação imersiva, multicanais, várias narrativas submersas são reveladas por meio da difícil travessia, do sonho interrompido e da longa espera em campos de refúgio. Em alguns momentos, temos a paisagem do mar e da travessia, sobrepondo a vida cotidiana e os mapas desenhados, que sobrevivem como testemunhos silenciosos. Em outros momentos, a narrativa entrecortada e fragmentos do corpo tornam-se tema central como local de memória, de suspensão e também de protesto. As múltiplas projeções propõem uma reflexão em que a travessia pelo oceano é também uma travessia de vida. As narrativas submersas aparecem, desaparecem e renascem, ousando uma variedade de vocabulários sonoro/visuais capazes de construir uma experiência reflexiva.

Este trabalho é uma construção de histórias humanas únicas, com variantes dramáticas, dentro da realidade confusa e incerta que envolve milhares de pessoas. São histórias de sensibilidades entre o sonho de uma vida melhor, o pesadelo da travessia e um futuro com bases desconhecidas. São histórias, permeadas por sonhos e percalços, daqueles que deixaram suas terras natais. Nessa direção, este projeto reúne grupos de testemunhos e suas singularidades, não só para confrontá-las, mas também para explorar os hibridismos visuais e sonoros dentro da proposta de documentário artístico.

\section{Seus temas fundamentais}

\section{Tradução e Montagem}

O processo de tradução articula-se no confronto e nas conexões entre diferentes linguagens. A tradução assume o formato de um procedimento de interpretação a partir da inter-relação entre formas distintas, gerando um novo resultado híbrido. Sendo assim, a tradução é também um operador de montagem, que tem como objetivo a busca de conexão, de compreensão entre diferentes pensamentos.

A montagem é, por sua vez, a possibilidade de a imagem ultrapassar a realidade em que foi produzida e assumir outros formatos. Aqui, a montagem tomou a frente, tornou-se a maneira definitiva de "amarrar" todo o processo de tradução visual, verbal, conceitual e sonoro, mostrando-se como tal. 
Vulnerabilidade humana na onda migratória

A vulnerabilidade se faz presente nos testemunhos de pessoas que desapareceram como indivíduos, que vivem sem documentos, em meio à impossibilidade legal e social, e que estão à espera de soluções políticas. Em contraste com a sociedade do imediatismo, tem-se a espera do migrante, dentro de centros de acolhimento, unida à reflexão da própria existência, às memórias e ao sonho de um futuro melhor.

Torna-se fundamental entender que o processo de migração contemporânea, mais do que um movimento espontâneo, representa um pedido de ajuda e de inclusão. Captar relatos testemunhais implica adotar a ética da escuta e valorizar a construção de narrativas pela inclusão da voz do outro.

\section{Hibridismo tecnológico}

A questão prática implica a necessidade de ampliar o campo de pesquisa em termos tecnológicos e elaborar novas lógicas organizadoras. Tais lógicas pretendem se constituir no trânsito entre os campos da subjetividade e da objetividade, ao mesmo tempo que servem de base para a proposição de outras linguagens.

Trata-se de uma abordagem que altera a estabilidade da narrativa linear, por meio da alternância de sons, palavras e imagens. O vídeo e a multimídia absorveram esses conhecimentos e deles se valem para criar novas possibilidades e novas metodologias de construção.

\section{A sonorização em multicanais}

Em termos gerais, fica fácil entender como o universo complexo de sons é capaz de produzir verdadeiras paisagens sensíveis. Trata-se de incorporar a força dos ruídos originais, para trabalhar novas combinações atreladas aos movimentos da realidade contemporânea, que, neste caso, são as migrações.

A instalação conta com um sistema computadorizado, em seis diferentes canais, com caixas de som que reproduzem sons documentais e ambientam todo o espaço expositivo. As captações são organizadas em seis grupos sonoros e passam pela travessia no mar, por ruídos de barcos e águas, por rezas árabes, cantos captados dentro de campos de refugiados, passos e sons do corpo marcando questões humanas, para, então, construírem uma paisagem sonora.

A montagem apresenta como resultado final um testemunho construído por sobreposições e cortes em imagens, movimentos e sons, mediados pela ideia de filme/ensaio para um discurso documental.

Roda Viva foi elaborado em 2018, como primeira etapa deste projeto. É pensado como uma ecologia de sons e ruídos sobre a onda migratória 
contemporânea; ele é o resultado de uma pesquisa realizada de 2014 a 2018, que inclui inúmeras viagens para a Grécia, Malta e Lampeduza, e tem como objetivo recriar passagens sonoras sobre pessoas em estado de refúgio e suas travessias. Nessa obra, sons são canais para desafiar a calma e o silêncio das zonas de conforto intelectual e interpretativo, que camuflam a realidade das migrações contemporâneas e as consequentes mudanças de identidade, enfocando o caso da chamada "crise dos refugiados", especialmente na Grécia e na Itália.

Roda Viva é um trabalho sonoro-documental que investe na capacidade de um objeto ser portador de uma paisagem sonora e imersiva, possibilitando experimentar, testar e incorporar a força dos ruídos originais, para trabalhar as questões atreladas a realidades distantes. Roda Viva traz ao público uma experiência sonora específica, a oportunidade de ativar a memória por meio dos sons e reconstruir em sua própria imaginação as questões do refúgio, mesmo sem que esse seja uma experiência pessoal. Os sons traduzem as diferentes passagens desde a travessia pelo mar para um destino desconhecido até o cotidiano da espera corrosiva em campos de contenção.

Com o objetivo de mostrar a porosidade do documentário e tocar a vulnerabilidade humana na onda migratória, foram eleitos alguns temas, que foram organizados em grupos sonoros - sons contínuos do corpo humano trazendo a emergência da realidade, barulhos da água e ruídos de motores de barcos, bowls e rezas árabes, crianças no campo brincando e cantando, cantos e músicas dos refugiados captados diretamente em campos -, para, então, construírem uma paisagem imersiva.

\section{Banco geral de dados: mixagem, legendagem e tratamento}

Em função do tipo de arquivo necessário para este trabalho, foi construído um banco de dados complexo dividido em três etapas: Banco de dados de testemunhos, que aborda basicamente grupos sobre os seguintes temas: sonho, travessia, espera e futuro; Banco de dados de imagens em movimento, cujos tópicos serão agrupados para a construção de uma narrativa visual e trazem temas como: águas, barcos, cotidiano no campo, ações em frente ao mar, movimentos do vento, detalhes do campo e rastros da travessia; por fim, o Banco de dados de sons, já citado na instalação sonora Roda Viva.

Cada arquivo de imagem e som integrante desse banco foi editado individualmente, ou seja, cada pequeno clipe de imagem em vídeo tem um tempo específico, passou por um processo de colorização, de equalização de som, fusões e uma longa pesquisa de arquitetura de movimentos e sons. A tradução e legendagem dos arquivos também é decisiva, pois a descrição textual de cada fala, onde houver testemunhos, é fundamental para a construção de uma narrativa. A exceção será nos momentos sem fala, em silêncio, onde haverá outra construção sonora. 


\section{Imagens}

Roda Viva

Imagens integrantes da Exposição Retrotopias, São Paulo, SP, 2018.

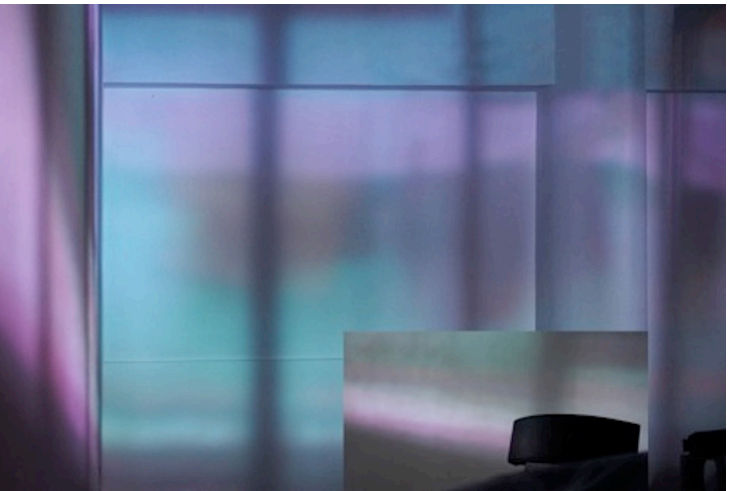

Fig 1. Roda Viva I

Fonte: Guggisberg, S.

Fig 2. Roda Viva II

Fonte: Orth, Mauricio.
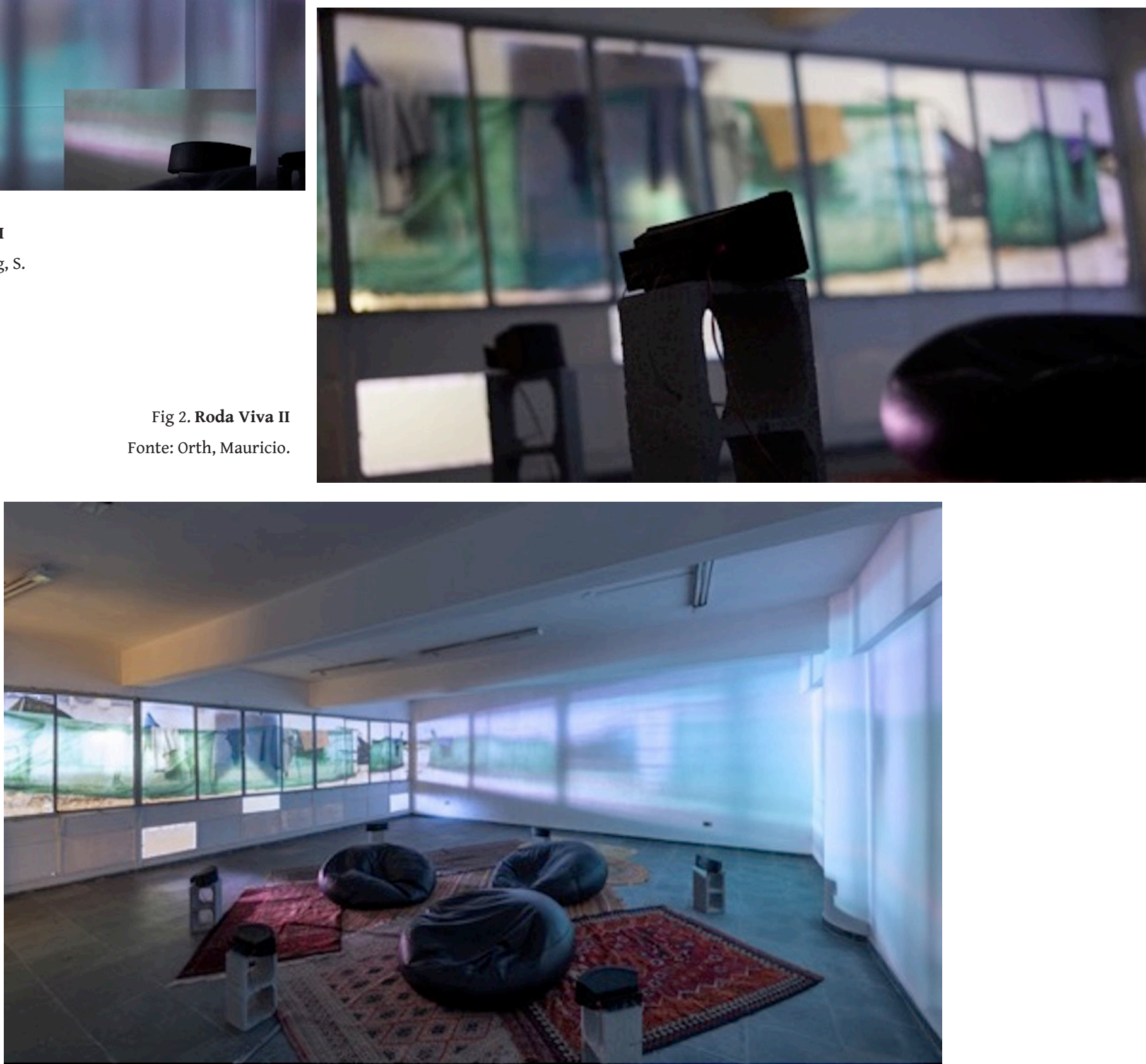

Fig 3. Roda Viva III

Fonte: Musa, Ding. 
Testemunhos de Passagem

Simulações produzidas pela artista.

Fig 4. Simulação I Fonte: Guggisberg, S.

Fig 5. Simulação II

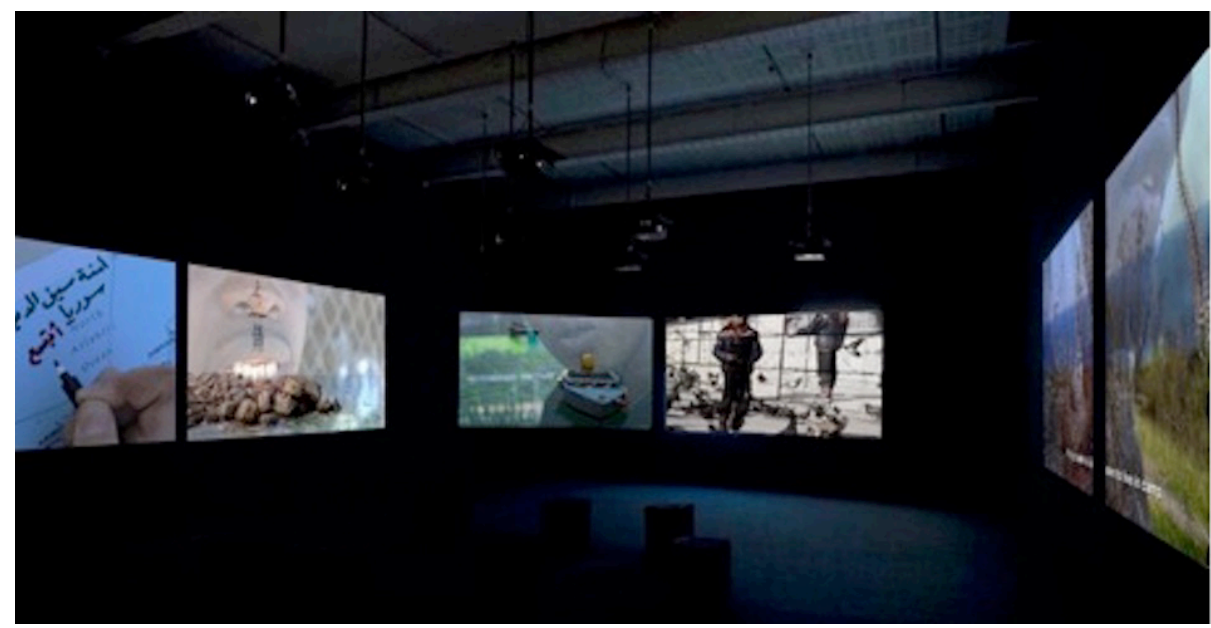

Fonte: Guggisberg, S.

Fig 6. Simulação III Fonte: Guggisberg, S.

Fig 7. Simulação IV Fonte: Guggisberg, S.
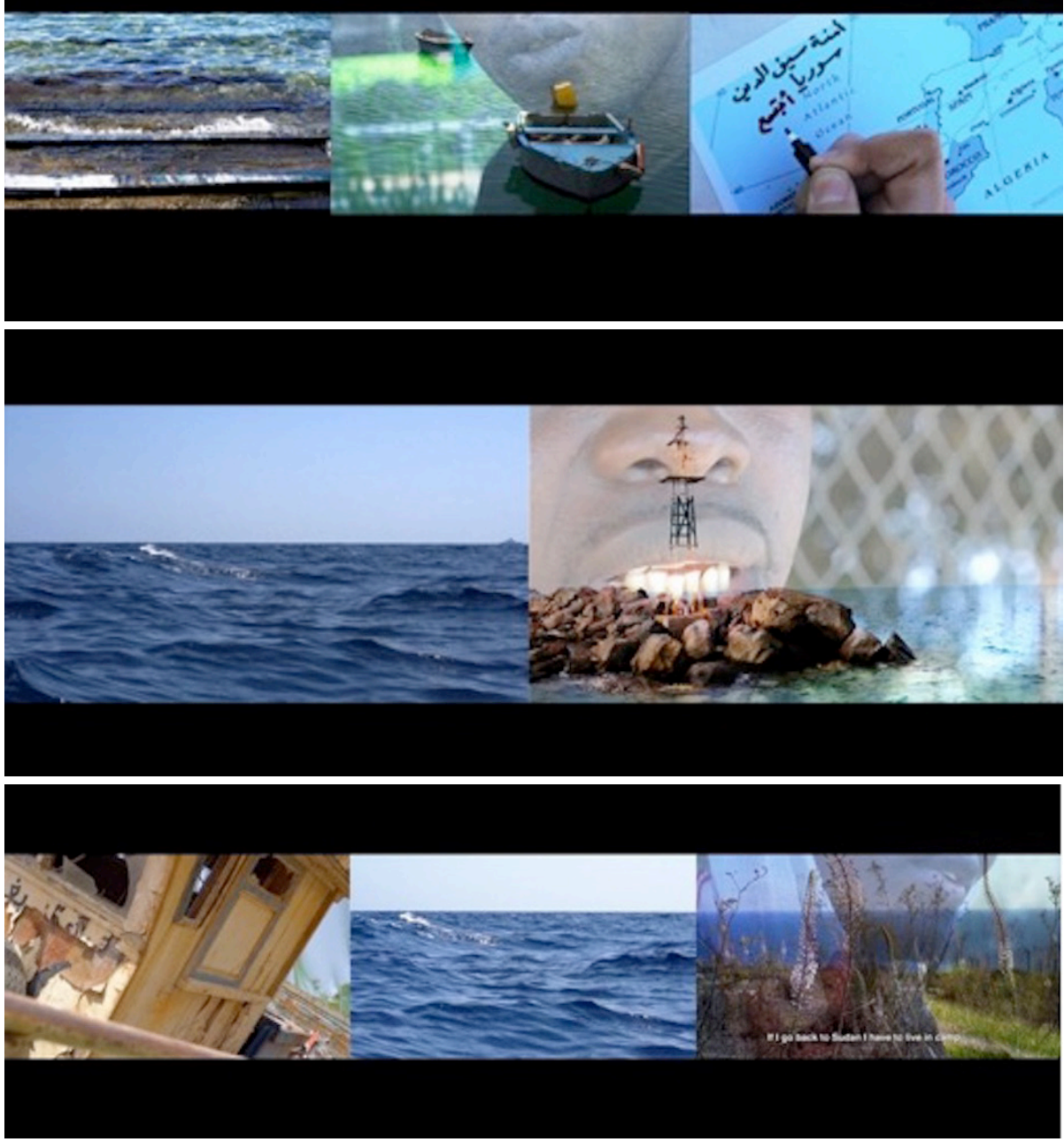

DATJournal v.4 n.3 2019 
Fig 8. Simulação V Fonte: Guggisberg, S.

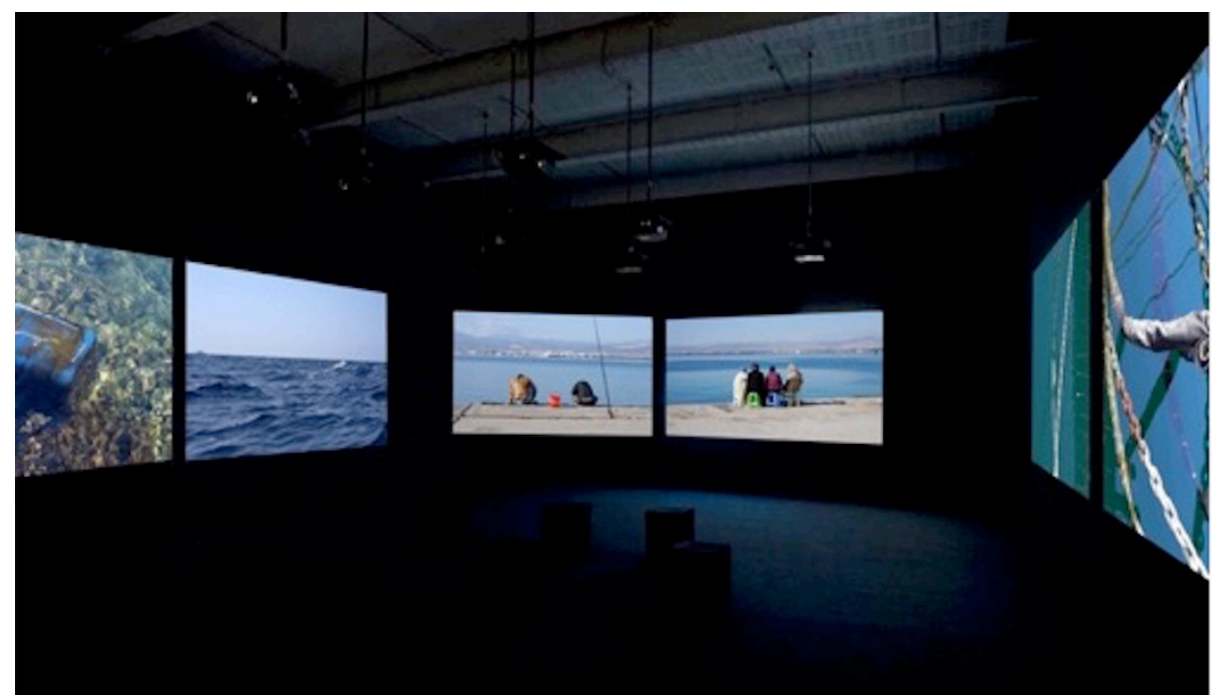

Fig 9. Simulação VI

Fonte: Guggisberg, $\mathrm{S}$.

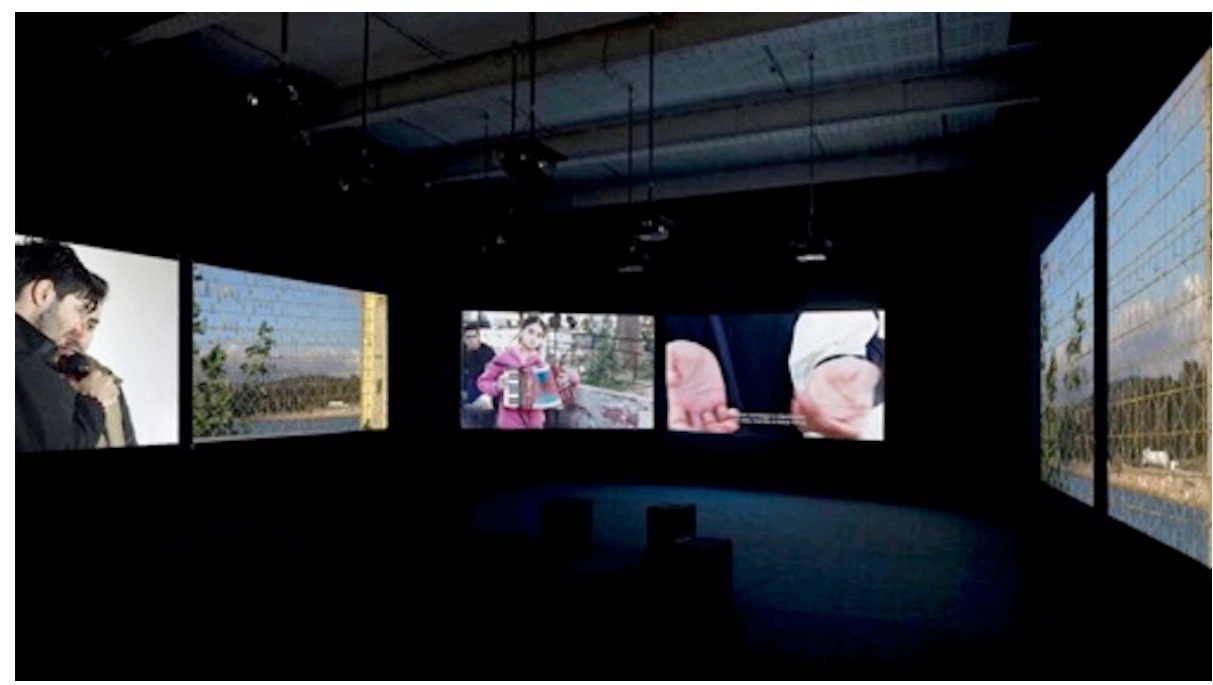

1 A noção de Documentação Performativa de Saberes é uma proposta desenvolvida em minha tese de doutorado intitulada Redes de imagens, memórias e testemunhos: por uma documentação performativa de saberes, defendida em 2014, na PUC-SP, com bolsa Fapesp. Essa noção está relacionada ao conceito de Ecologia de Saberes, proposto por Santos (2010)

2 The notion of Performative Documentation of Knowledge is a proposal developed in my doctorate thesis dissertation entitled Networks of images, memories and testimonies: for a performative documentation of knowledge, defended in 2014, at PUC-SP, with Fapesp scholarship. This notion is related to the concept of Knowledge Ecology, proposed by Boaventura Sousa Santos (2010). 


\section{Referências}

ARANTES, Priscila; OlIVEIRA, Mirtes. Design e Ativismo. DATJournal Design Art and Technology, v. 4, n. 2 (2019). Editorial, p. 1-2. Disponível em: <https://datjournal.anhembi. br/dat/article/view/124/103>. Acesso em: 8 nov. 2019. DOI: https://doi.org/10.29147/dat. v4i2.124.

LIMA, Leonardo; PRADO, Gilbertto. Interactive Digital Images. DATJournal Design Art and Technology, [S.l.], v. 3, n. 2, p. 43-71, nov. 2018. Disponível em: <https://datjournal.anhembi.br/ dat/article/view/86/74>. Acesso em: 8 nov. 2019. DOI: https://doi.org/10.29147/dat.v3i2.86.

GREINER, Christine. $\mathrm{O}$ corpo em crise: novas pistas e o curto-circuito das representações. São Paulo: Annablume, 2010.

GUGGISBERG, Sonia. Redes de imagens, memórias e testemunhos: por uma documentação performativa de saberes. São Paulo: Intermeios, 2017.

GUGGISBERG, Sonia. Roda Viva (Life Wheel). Proceedings of Artech 2019, 9th International Conference on Digital and Interactive Arts. Braga, Portugal. DOI: https://doi. org/10.1145/3395852.3359932.

PARENTE, André. A forma cinema: variações e rupturas. In: MACIEL, Katia (Org.). Transcinemas. Rio de Janeiro: Contra Capa, 2009.

Tramas da rede: novas dimensões estéticas e políticas da comunicação. Porto Alegre: Sulina, 2004.

PRADO, Gilbertto. Arte telemática: dos intercâmbios pontuais aos ambientes virtuais multiusuário. São Paulo:Itaú Cultural, 2003.

PRADO, Gilbertto; TAVARES, Monica; ARANTES, Priscila (Org.). Diálogos transdisciplinares: arte e pesquisa. São Paulo: ECA/USP, 2016.

SANTOS, Boaventura de Sousa. o futuro do Fórum Social Mundial: o trabalho da tradução. Revista del Observatorio Social de América Latina, 2004, p. 77-90. Disponível em: <https://www.ces.uc.pt/myces/UserFiles/livros/65_Futuro\%20FSM\%20-\%200\%20trabalho\%20 da\%20traducao_OSAL_2004.pdf>. Acesso em: 8 nov. 2019.

; MENESES, Maria Paula (Org.). Epistemologias do sul. São Paulo: Cortez, 2010. 